American J. of Engineering and Applied Sciences 3 (1): 133-137, 2010

ISSN 1941-7020

(C) 2010 Science Publications

\title{
Confined High Strength Concrete Columns: An Experimental Study
}

\author{
Jagannathan Saravanan, K. Suguna and P.N. Raghunath \\ Department of Structural Engineering, Annamalai University, Annamalainagar-608002, India
}

\begin{abstract}
Problem statement: An experimental study on GFRP confined high strength concrete columns has been carried out with a view to evaluate its performances under uni-axial compression in terms of load and deformation capacity. Approach: High strength concrete columns strengthened with different configuration and stiffness of GFRP wraps were tested under axial compression until failure. Their response evaluated at different load levels. Results: The test results clearly indicated GFRP wrapped high strength concrete columns exhibit enhances performance. Conclusion: The study concluded that the three GFRP materials attempted UDC GFRP provided the maximum benefit with respect to load and deformation.
\end{abstract}

Key words: Confinement, ductility, GFRP, strength

\section{INTRODUCTION}

Concrete with strengths higher than $40 \mathrm{MPa}$ is generally referred to as high strength concrete. Some basic concepts relating to strength and ductility have been introduced in ACI code with respect to the compression member (American Concrete Institute, 1999). With developments in technology, the use of high strength concrete members has proved to be most promising in terms strength, stiffness, durability and economy (Raviz and Saatcioglu, 1997). As the strength of concrete increases, it becomes more brittle. The lack of ductility of high strength concrete columns can result in sudden failure. Several research works have proved that the strength and ductility can be improved by the use of spiral confinement, rectangular and circular lateral ties (Yong et al., 1988). In recent years, external wrapping has been identified as an effective method of confining concrete. Among the various materials available for the purpose, FRP has proved to be more beneficial. The application of FRP in the construction industry can eliminate some unwanted properties of high strength concrete, such as the brittle behavior of high strength concrete. FRP is particularly useful for strengthening columns and other unusual shapes. Several research studies have been reported an improving the strength and ductility of normal strength columns. Only limited literature is available on enhancing the ductility of high strength concrete column members. Hence an attempt has been made to investigate the strength and ductility performance of high strength concrete columns with external GFRP wrapping (Demer and Neale, 1999; Mirmiran and Shahawy, 1997; Hadi and Li, 2004).
Research significance: In recent years the ductility has becomes an important design parameter for better performance under varying environments. In particular ductility of column places a crucial load in the event of the earthquakes. Ductility can be important by internal confinement or external confinement. High strength concrete columns inherently lack ductility. In this research an attempt is made to study the strength deformation response of HSC columns utilizing the technique of external confinement with fiber reinforced polymer composites.

\section{MATERIALS AND METHODS}

An experimental investigation has been conducted on 7 column specimens having $150 \mathrm{~mm}$ diameter and a slenderness ratio of 32 . The longitudinal reinforcement consisted of 6 bars of $8 \mathrm{~mm}$ diameter and internal ties consisted of $6 \mathrm{~mm}$ diameter bars at $115 \mathrm{~mm}$ spacing. Out of the seven columns, one reference column was tested without any wrapping and the remaining 6 columns were wrapped with GFRP of varying configuration with different thickness. The designation of specimens and their details are presented in Table 1.

\begin{tabular}{llll}
\multicolumn{2}{l}{ Table 1: Specimen details } \\
\hline $\begin{array}{l}\text { Specimen } \\
\text { Designation }\end{array}$ & $\begin{array}{l}\text { Diameter } \\
(\mathrm{mm})\end{array}$ & $\begin{array}{l}\text { Type of GFRP } \\
(\mathrm{mm})\end{array}$ & $\begin{array}{l}\text { Thickness of GFRP } \\
(\mathrm{mm})\end{array}$ \\
\hline R0 & 150 & - & 0 \\
CSM3 & 150 & CSM & 3 \\
CSM5 & 150 & CSM & 5 \\
WR3 & 150 & WR & 3 \\
WR5 & 150 & WR & 5 \\
UDC3 & 150 & UDC & 3 \\
UDC5 & 150 & UDC & 5 \\
\hline
\end{tabular}

Corresponding Author: Jagannathan Saravanan, Department of Structural Engineering, Annamalai University, Annamalainagar-608002, India 
Am. J. Engg. \& Applied Sci., 3 (1): 133-137, 2010

Table 2: Properties of Glass Fiber Reinforced Polymer (GFRP) Wraps

\begin{tabular}{llllc}
\hline Type of fiber in GFRP & Thickness $(\mathrm{mm})$ & Tensile strength (Mpa) & Ultimate elongation (\%) & Elasticity modulus (Mpa) \\
\hline CSM & 3 & 126.20 & 1.60 & 7467.46 \\
CSM & 5 & 156.00 & 1.37 & 11386.86 \\
UDC & 3 & 446.90 & 3.02 & 13965.63 \\
UDC & 5 & 451.50 & 2.60 & 17365.38 \\
WR & 3 & 147.40 & 2.15 & 6855.81 \\
WR & 5 & 178.09 & 1.98 & 8994.44 \\
\hline
\end{tabular}

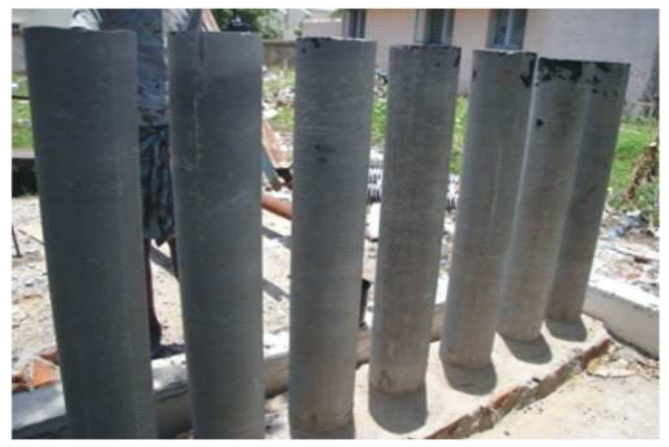

Fig. 1: Asbestos cement pipe moulds

Material properties: The concrete used for casting the specimens was designed for target strength $60 \mathrm{MPa}$. The mix ratio adopted was 1:173:2.51:0.34:0.8\% (cement: Fine aggregate: Coarse aggregate: Water: Hyperplastizicer percentage by weight of binder). The characteristic compressive strength achieved was 63.64 MPa. The steel used for longitudinal reinforcement was ribbed steel with an yield strength of $415 \mathrm{MPa}$ and mild steel with an yield strength of $250 \mathrm{MPa}$ was used for the lateral ties. The properties of GFRP used for the investigation are presented in Table 2.

Preparation and casting of specimens: The specimens were prepared by casting them in asbestos cement pipe moulds. After sizing, the pipes were placed firmly in position using a lean mix mortar at the base. The bottom faces of the pipes were covered with polymer sheets to avoid any leaks. Cover blocks were placed at appropriate places to ensure adequate cover to the reinforcement. The interior of the pipes was applied a liberal coat of lubricating oil to prevent concrete from adhering to the asbestos cement pipe. Steel reinforcement cage was prepared for each specimen according to the requirements. The reinforcement cages were placed into the asbestos cement pipe formwork and positioned in such a way that pre determined cover was available on all sides. The designed concrete mix was filled into the moulds in layers. Adequate compaction was carried out using needle vibrator to avoid honey combing. Figure 1-4 show the preparation and casting of specimens.

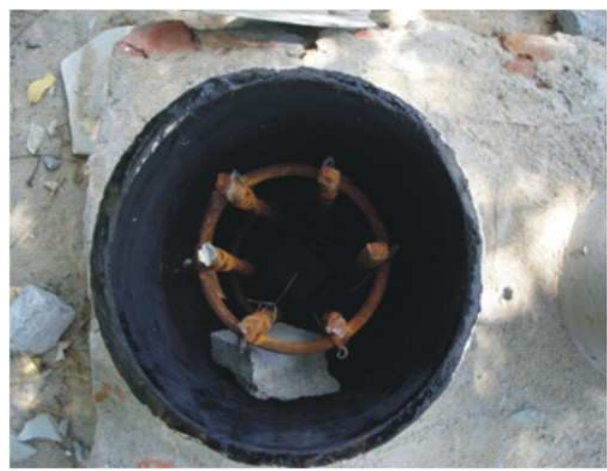

Fig. 2: Reinforcement cage with cover block

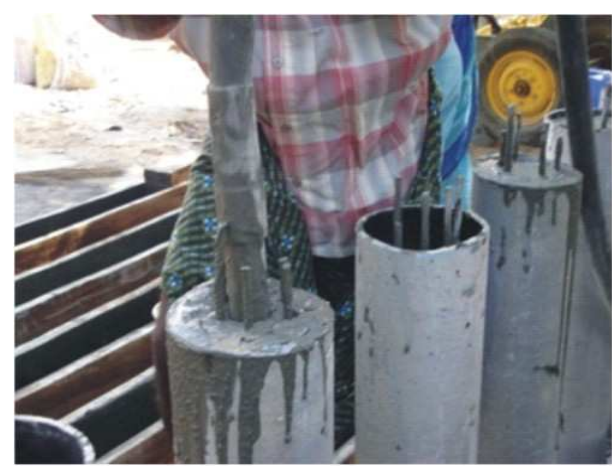

Fig. 3: Casting under progress

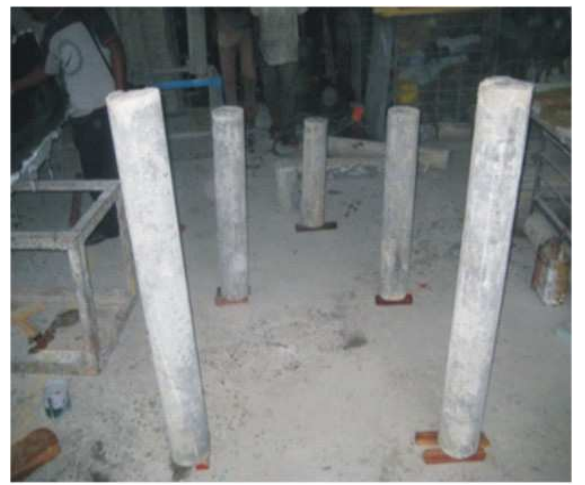

Fig. 4: Specimen after demoulding

The specimens were removed from moulds without any damage and cured in a standard manner for a period of 28 days. 
Wrapping with FRP: The cured specimens were prepared for wrapping with FRP. The surfaces of the specimens were ground with a high grade grinding wheel to remove loose and deleterious material from the surface. A jet of compressed air was applied on the surface to blow off any dust and dirt. Then, all surface cavities were filled up with mortar putty to ensure a uniform surface and to ensure proper adhesion of FRP to concrete surface. The wrapped surfaces were gently pressed with a rubber roller to ensure proper adhesion between the layers and proper distribution of resin. Figure 5 and 6 show the application of FRP wrap on the surface of the column specimen.

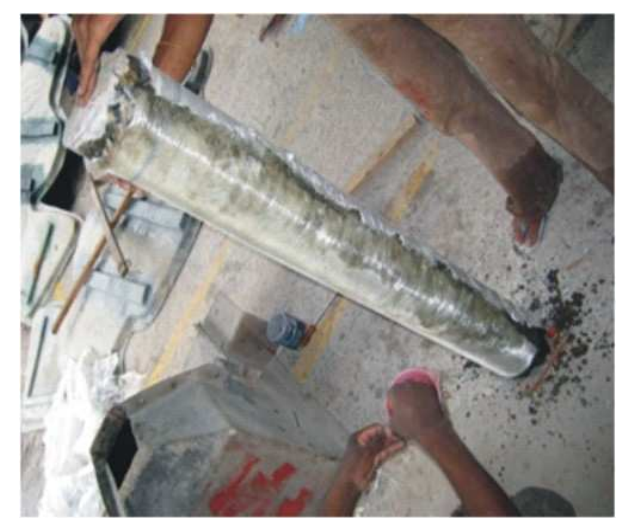

Fig. 5: Wrapping under progress

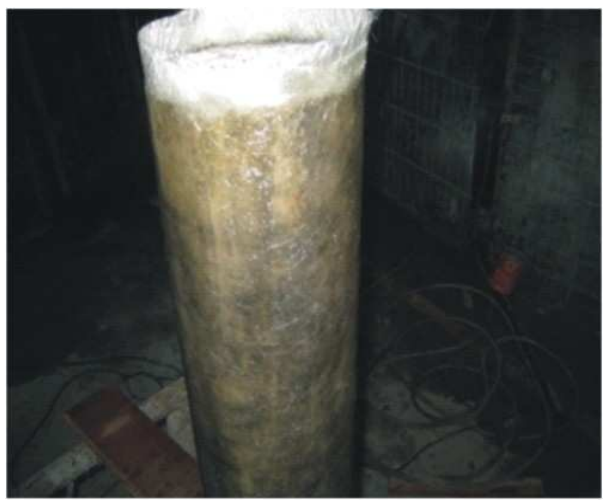

Fig. 6: Wrapped specimen
Experimental set-ups: Testing of specimens was carried out in a loading frame of $2000 \mathrm{KN}$ capacity. The instruments used for testing included deflectometers having a least count of $0.01 \mathrm{~mm}$ and a lateral extensometer used for column testing. The specimen was placed with capping at both ends. The load was applied using a hydraulic jack in uniform increments of $25 \mathrm{kN}$. Axial compression was measured using two dial gauges placed at top and bottom of the specimen. The dialution was measured using the lateral extensometer.

\section{RESULTS}

The results relating to the ultimate load, ultimate stress, ultimate axial deflection and ultimate lateral deflection of the specimens are presented in Table 3. The ultimate load carrying capacity, ultimate axial strain and ultimate lateral strain of tested columns are shown in Fig. 7-9. It is clear that ultimate stress, ultimate axial strain and ultimate lateral strain increases for different GFRP wraps.

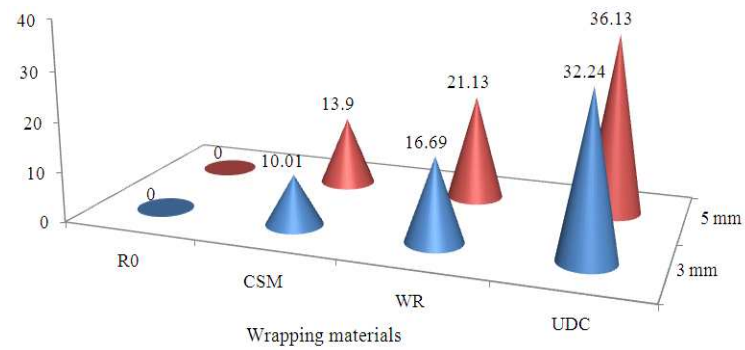

Fig. 7: Ultimate stress in all specimens

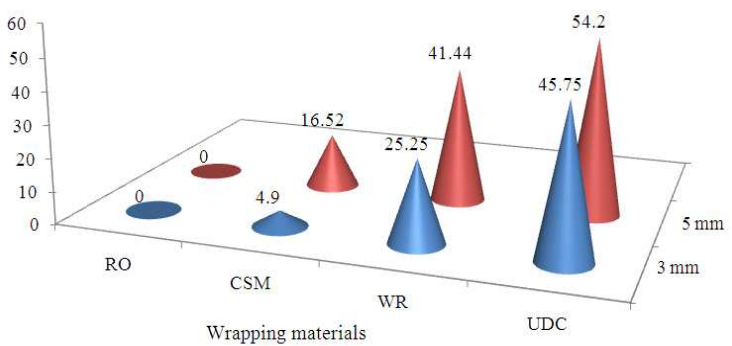

Fig. 8: Ultimate axial strain in all specimens

Table 3: Test results

\begin{tabular}{lllllll}
\hline $\begin{array}{l}\text { Specimen } \\
\text { designation }\end{array}$ & $\begin{array}{l}\text { Ultimate load } \\
(\mathrm{kN})\end{array}$ & $\begin{array}{l}\text { Ultimate axial } \\
\text { stress }(\mathrm{MPa})\end{array}$ & $\begin{array}{l}\text { Ultimate axial } \\
\text { deflection }(\mathrm{mm})\end{array}$ & $\begin{array}{l}\text { Ultimate lateral } \\
\text { deflection }(\mathrm{mm})\end{array}$ & $\begin{array}{l}\text { Ultimate axial } \\
\text { micro strain }\end{array}$ & $\begin{array}{l}\text { Ultimate lateral } \\
\text { micro strain }\end{array}$ \\
\hline R0 & 900 & 50.92 & 3.45 & 0.37 & 2875 & 2472 \\
CSM3 & 990 & 56.02 & 3.62 & 0.42 & 3016 & 2861 \\
WR3 & 1050 & 59.41 & 4.34 & 0.45 & 3616 & 3031 \\
UDC3 & 1190 & 67.34 & 5.03 & 0.58 & 4191 & 3894 \\
CSM5 & 1025 & 58.00 & 4.02 & 0.44 & 3350 & 2997 \\
WR5 & 1090 & 61.68 & 4.88 & 0.54 & 4066 & 3606 \\
UDC5 & 1225 & 69.32 & 5.32 & 0.59 & 4433 & 3979 \\
\hline
\end{tabular}




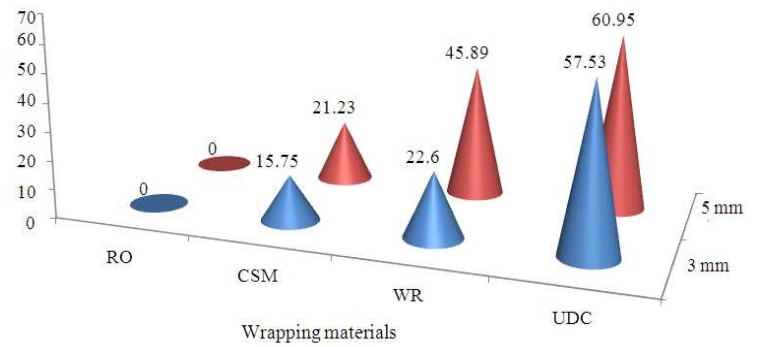

Fig. 9: Ultimate lateral strain in all specimens

\section{DISCUSSION}

Effect on strength: The increase in ultimate strength was found to be a $10.01 \%$ for specimen with $3 \mathrm{~mm}$ thick CSM wrapping and $13.90 \%$ for specimen with $5 \mathrm{~mm}$ thick CSM wrapping when compared to the reference column. The increase in ultimate strength was found to be a $16.69 \%$ for specimen with $3 \mathrm{~mm}$ thick WR wrapping and $21.13 \%$ for specimen with $5 \mathrm{~mm}$ thick WR wrapping when compared to the reference column. The increase in ultimate strength was found to be a $32.24 \%$ for specimen with $3 \mathrm{~mm}$ thick UDC wrapping and $36.16 \%$ for specimen with $5 \mathrm{~mm}$ thick UDC wrapping when compared to the reference column. The increase in ultimate stress is shown in Fig. 7.

The increase in ultimate strength was found to be a $6.05 \%$ for specimen with $3 \mathrm{~mm}$ thick WR wrapping when compared to the specimen with CSM wrapping of same thickness. The increase in ultimate strength was found to be a $6.34 \%$ for specimen with $5 \mathrm{~mm}$ thick WR wrapping when compared to the specimen with CSM wrapping of same thickness. The increase in ultimate strength was found to be a $20.26 \%$ for specimen with $3 \mathrm{~mm}$ thick UDC wrapping when compared to the specimen with CSM wrapping of same thickness. The increase in ultimate strength was found to be a $19.52 \%$ for specimen with $5 \mathrm{~mm}$ thick UDC wrapping when compared to the specimen with CSM wrapping of same thickness. The increase in ultimate strength was found to be a $13.35 \%$ for specimen with $3 \mathrm{~mm}$ thick UDC wrapping when compared to the specimen with WR wrapping of same thickness. The increase in ultimate strength was found to be a $12.39 \%$ for specimen with $5 \mathrm{~mm}$ thick UDC wrapping when compared to the specimen with WR wrapping of same thickness.

Effect on deformation: The increase in axial strain was found to be a $4.90 \%$ for specimen with $3 \mathrm{~mm}$ thick CSM wrapping and $16.52 \%$ for specimen with $5 \mathrm{~mm}$ thick CSM wrapping when compared to the reference column. The increase in axial strain was found to be a
$25.25 \%$ for specimen with $3 \mathrm{~mm}$ thick WR wrapping and $41.44 \%$ for specimen with $5 \mathrm{~mm}$ thick WR wrapping when compared to the reference column. The increase in axial strain was found to be a $45.75 \%$ for specimen with $3 \mathrm{~mm}$ thick UDC wrapping and $54.20 \%$ for specimen with $5 \mathrm{~mm}$ thick UDC wrapping when compared to the reference column. The increase in ultimate axial strain is shown in Fig. 8.

The increase in ultimate axial strain was found to be a $19.89 \%$ for specimen with $3 \mathrm{~mm}$ thick WR wrapping when compared to the specimen with CSM wrapping of same thickness. The increase in ultimate axial strain was found to be a $21.39 \%$ for specimen with $5 \mathrm{~mm}$ thick WR wrapping when compared to the specimen with CSM wrapping of same thickness. The increase in ultimate axial strain was found to be a $38.95 \%$ for specimen with $3 \mathrm{~mm}$ thick UDC wrapping when compared to the specimen with CSM wrapping of same thickness. The increase in ultimate axial strain was found to be a $32.33 \%$ for specimen with $5 \mathrm{~mm}$ thick UDC wrapping when compared to the specimen with CSM wrapping of same thickness. The increase in ultimate axial strain was found to be a $15.90 \%$ for specimen with $3 \mathrm{~mm}$ thick UDC wrapping when compared to the specimen with WR wrapping of same thickness. The increase in ultimate axial strain was found to be a $9.02 \%$ for specimen with $5 \mathrm{~mm}$ thick UDC wrapping when compared to the specimen with WR wrapping of same thickness.

The increase in lateral strain was found to be a $15.75 \%$ for specimen with $3 \mathrm{~mm}$ thick CSM wrapping and $21.23 \%$ for specimen with $5 \mathrm{~mm}$ thick CSM wrapping when compared to the reference column. The increase in lateral strain was found to be a $22.60 \%$ for specimen with $3 \mathrm{~mm}$ thick WR wrapping and $45.89 \%$ for specimen with $5 \mathrm{~mm}$ thick WR wrapping when compared to the reference column. The increase in lateral strain was found to be a $57.53 \%$ for specimen with $3 \mathrm{~mm}$ thick UDC wrapping and $60.95 \%$ for specimen with $5 \mathrm{~mm}$ thick UDC wrapping when compared to the reference column. The increase in ultimate lateral strain is shown in Fig. 9.

The increase in ultimate lateral strain was found to be a $5.92 \%$ for specimen with $3 \mathrm{~mm}$ thick WR wrapping when compared to the specimen with CSM wrapping of same thickness. The increase in ultimate lateral strain was found to be a $20.24 \%$ for specimen with $5 \mathrm{~mm}$ thick WR wrapping when compared to the specimen with CSM wrapping of same thickness. The increase in ultimate lateral strain was found to be a $36.09 \%$ for specimen with $3 \mathrm{~mm}$ thick UDC wrapping when compared to the specimen with CSM wrapping of same thickness. The increase in ultimate lateral 
strain was found to be a $32.76 \%$ for specimen with $5 \mathrm{~mm}$ thick UDC wrapping when compared to the specimen with CSM wrapping of same thickness. The increase in ultimate lateral strain was found to be a $28.49 \%$ for specimen with $3 \mathrm{~mm}$ thick UDC wrapping when compared to the specimen with WR wrapping of same thickness. The increase in ultimate lateral strain was found to be a $10.33 \%$ for specimen with $5 \mathrm{~mm}$ thick UDC wrapping when compared to the specimen with WR wrapping of same thickness.

\section{CONCLUSION}

Based on the results presented, the following conclusions are drawn:

- The GFRP significantly improved the ultimate stress, ultimate axial strain and ultimate lateral strain of the column when compared to the reference column

- The maximum ultimate stress was increased by $36.13 \%$ for $5 \mathrm{~mm}$ thick UDC wrapping when compared to reference column

- The maximum ultimate axial strain was increased by $54.23 \%$ for $5 \mathrm{~mm}$ thick UDC wrapping when compared to reference column

- The maximum ultimate lateral strain was increased by $60.95 \%$ for $5 \mathrm{~mm}$ thick UDC wrapping when compared to reference column

\section{REFERENCES}

American Concrete Institute (ACI), 1999. Building code Requirements for Structural Concrete (31899) and Commentary (318R-99). Farmington Hills, Michicigan. http://www.concrete.org/PUBS/newpubs/318-05.htm

Demer, M. and K.W. Neale, 1999. Confinement of reinforced concrete columns with fiber-reinforced composite sheet-an experimental study. Can. J. Civil Eng., 26: 226-241. DOI: 10.1139/cjce-26-2-226

Hadi, M.N.S. and J. Li, 2004. External reinforcement of high strength concrete columns. J. Comp. Struct., 65: 279-287. DOI: 10.1016/j.compstruct2003.11.003

Mirmiran, A. and M. Shahawy, 1997. Behavior of concrete columns confined by fiber composites. J. Struct. Eng., 123: 583-590. DOI: 10.1061/(ASCE)0733-9445(1997) 123:5(583)

Raviz, S.R. and M. Saatcioglu, 1997. Strength and deformability of confined high-strength concrete columns. ACI Struct. J., 91: 678-687. http://www.concrete.org/PUBS/JOURNALS/OLJD etails.asp?Home=SJ\&ID=1499

Yong, Y.K., M.G. Nour and E.G. Nawy, 1988. Behavior of laterally confined high strength concrete under axial loads. ASCE J. Strut. Eng., 114: $\quad 332-351 . \quad$ DOI: $10.1061 /(\mathrm{ASCE})$ 0733(1988)114:2(332) 